\title{
An Innovative Strategy Allowing a Holistic System Change towards Circular Economy within Supply-Chains
}

\author{
Jeff Mangers *, Meysam Minoufekr, Peter Plapper (D) and Sri Kolla (D) \\ Faculty of Science, Technology and Medicine, University of Luxembourg, 6, rue Coudenhove-Kalergi, \\ L-1359 Luxembourg, Luxembourg; meysam.minoufekr@uni.lu (M.M.); peter.plapper@uni.lu (P.P.); \\ sri.kolla@uni.lu (S.K.) \\ * Correspondence: jeff.mangers@uni.lu; Tel.: +352-46-66-44-5710
}

\section{check for} updates

Citation: Mangers, J.; Minoufekr, M.; Plapper, P.; Kolla, S. An Innovative Strategy Allowing a Holistic System Change towards Circular Economy within Supply-Chains. Energies 2021, 14, 4375. https://doi.org/10.3390/ en14144375

Academic Editors: Geerten Van De Kaa, Breno Nunes, Paulo

Antônio Zawislak, Leon Pretorius and Idiano D'Adamo

Received: 22 April 2021

Accepted: 15 July 2021

Published: 20 July 2021

Publisher's Note: MDPI stays neutral with regard to jurisdictional claims in published maps and institutional affiliations.

Copyright: (C) 2021 by the authors. Licensee MDPI, Basel, Switzerland. This article is an open access article distributed under the terms and conditions of the Creative Commons Attribution (CC BY) license (https:/ / creativecommons.org/licenses/by/ $4.0 /)$.

\begin{abstract}
The concept of the circular economy (CE) is receiving encouraging attention among scholars and practitioners, as a convenient solution to move away from the linear economy concept without neglecting the goals of sustainable development. The main goals of the $\mathrm{CE}$ are the closing of resource loops and the keeping of resources in the system for as long as possible at the highest utility level. However, as a result of the lack of internationally accepted definitions of the CE and several unsolved barriers, an excessive and inconsistent number of different $\mathrm{CE}$ applications exist. Most fields are mainly focusing on making a linear system circular instead of applying the CE principles in a holistic way. This paper presents a strategy to close the mentioned inconsistency gap, by contrasting currently discussed CE barriers and goals and thereof deriving two areas with a need for action (1. identifying the needed collection, sorting, and recovery infrastructure, and 2. developing circular product design guidelines). The strategy itself consists of connecting these two areas through an improved information exchange between the end-of-life (EOL) and beginning-of-life (BOL) of products. The result is CE design guidelines which are in accordance with the available or needed collection, sorting, and recovery infrastructure. The proposed strategy presents an innovative solution to apply CE principles in a holistic manner, based on EOL-driven product design.
\end{abstract}

Keywords: circular economy; sustainability; holistic strategy; system change; product-life-cycle; end-of-life; beginning-of-life; goals; barriers

\section{Introduction}

During the last years, the CE concept has gained the interest of scholars [1], researchers, professionals, and politicians [2], because it is considered as an operational method in which businesses can implement the concept of sustainable development [3]. CE is seen as a way to overcome the current dominant economic development model, the so-called "take, make, and dispose" [4], by promoting the adoption of closing-the-loop production patterns. In simple terms, the CE concept represents the most recent attempt to conceptualize the integration of economic activity and environmental wellbeing in a sustainable way [5-8].

A major criticism of the $\mathrm{CE}$ is that various possibilities for defining $\mathrm{CE}$ exist and thus a commonly accepted definition is missing [8,9]. This may lead to the ultimate collapse of the concept, or force it to remain in a deadlock due to permanent conceptual contention $[4,5,10]$. The same applies to the success of harmonizing assessment methods for CE among public, scientific, and private institutions, and across different materials (e.g., goods, waste, etc.) and scales (e.g., global economy, single-firm assessment) [11]. First efforts to define the $\mathrm{CE}$ on a national level and to provide guidelines on how to apply the CE were performed by Great Britain (BS 8001:2017) and France (XP X 30-901) and are currently being pursued on an international level by the ISO technical committee 323 (ISO/TC 323) [12]. Since the $\mathrm{CE}$ is not yet defined at an international level, and the aim of this paper is not to add a new definition of the CE, the formulated definition from [5] (pp. 224-225) will be used as reference in this publication: 
"A circular economy describes an economic system that is based on business models which replace the 'end-of-life' concept with reducing, alternatively reusing, recycling, and recovering materials in production/distribution and consumption processes, thus operating at the micro level (products, companies, consumers), meso level (eco-industrial parks) and macro level (city, region, nation, and beyond), with the aim to accomplish sustainable development, which implies creating environmental quality, economic prosperity, and social equity, to the benefit of current and future generations."

Besides the missing of an internationally accepted definition for the CE, several other barriers and hurdles exist which are preventing a successful paradigm change towards the CE. These can be divided into cultural, market, regulator, and technological barriers [13]. Overall, a lot of effort has already been invested to detect barriers which are hindering the successful implementation of the CE. Nevertheless, the majority of companies still adopt a linear approach or just focus on providing information to the end-user in order to maximize their satisfaction during the use phase, while only a small amount have approached the CE in a holistic way [14]. The same is valid for the current management of mining waste, which is still based on linear economy thinking and not really on a circular approach [15].

This gap between aiming to implement CE principles and applying them in a holistic manner is a widespread inconsistency. To resolve this gap, this paper contributes to the necessity to innovate new strategies on how to successfully apply CE principles in a holistic way. To do so, the currently discussed goals and targets of the CE within the literature are reviewed and can be summarized by the following three main goals:

1. Close and slow loops [16]

2. Minimize waste [17]

3. Sustainability [5]

By contrasting CE barriers with CE goals and visualizing them in an adapted butterfly, it was possible to highlight two areas with a need of action to initiate a successful paradigm change. This outlined the currently missing information exchange between the EOL and the BOL, which results in a complicated transition from the product use-phase towards the recovery phase. The presented strategy proposes a solution to enable a system change towards the CE within SCs.

By highlighting two areas with a need for action and outlining the subsequent relevance of enhancing the information exchange between EOL and BOL, this paper contributes to the necessity to innovate new strategies on how to successfully apply CE principles in a holistic way.

The remainder of the publication is structured as follows: in Section 2, a literature review regarding $\mathrm{CE}$ and its barriers and hurdles and its goals and targets is undertaken. In Section 3, the research methodology is visualized and explained within Section 3. Based on the literature review, the subsequent results chapter derives two areas with a need for action to enable a successful CE applicability and visualizes the findings in an adapted butterfly diagram. Finally, the gained insights are used to set up a new strategy for CE implementation, which aims to better connect the information exchange between EOL and BOL. The last two chapters focus on the discussion and conclusion of the findings and summarize the work.

\section{Literature Review}

For the following, the expression "resources" is used for products, parts, and materials, as well as waste, which can be considered as material without an identity. Additionally, the expression "R-infrastructure" is used for every infrastructure needed to bring resources back into a certain circle (e.g., recycle, repair, etc.). This can either be a recycling facility, a repairing facility, a secondhand selling shop, or any other uptake facility. The collection and sorting refer to the ability to catch resources after the use/consume phase and classify the resources accordingly. 
In the following, first the general aspects of the $\mathrm{CE}$ are reviewed, then we turn to the barriers and hurdles of the $\mathrm{CE}$, finally looking at the goals and targets of CE. To conclude the literature review, an identified gap is outlined.

\subsection{Circular Economy in a Nutshell}

One of the first mentions of sustainability was by the Club of Rome "The Limits to growth" [18] in 1972, which was later coined by the 1987 report "Our Common Future" by the World Commission of Environment and Development (WCED). They defined sustainable development as: "Sustainable development is development that meets the needs of the present without compromising the ability of future generations to meet their own needs" [19] (p. 41). More recently, in September 2015, the United Nations (UN) General Assembly adopted 17 Sustainable Development Goals (SDGs) as an integral part of the 2030 Agenda for Sustainable Development [20]. This was an important step to further promote sustainability on a global level. For ISO [21], sustainability encompasses three dimensions (economic, environmental, and social), which are interdependent and can be mutually reinforcing. These three dimensions are known as the three pillars of sustainability [22].

Overall, resources play a crucial role in delivering value to society, with increasing attention being paid to their sustainable use. A more recent goal is to close material loops and develop the economy towards more circular systems [23]. This is consonant with the cradle-to-cradle mindset of William McDonough and Michael Braungart [24], visualized by M. Geissdoerfer et al., [25] (Figure 1), depicting a sustainable business model as an extension of a traditional business model and a circular business model as an extension of a sustainable business model.

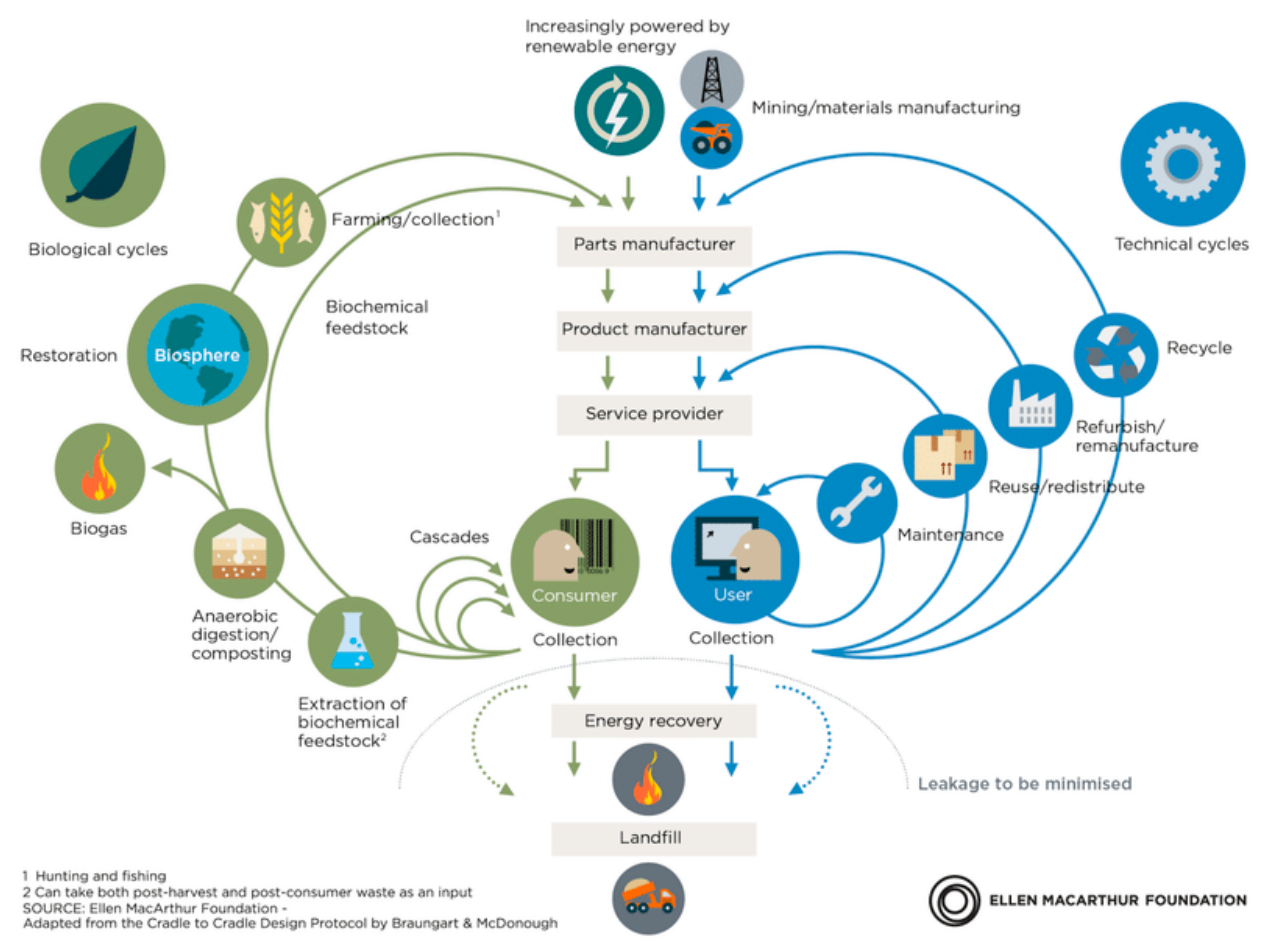

Figure 1. Outline of a circular economy technical and biological cycle [26].

Generally speaking, CE aims to keep products, components, and materials at their highest utility and value at all times and distinguishes between technical and biological cycles [26]. Most of the considered articles focus on the technical cycle and treat bio- and non-bio materials equally [16], or only consider the technical cycle of the EMF butterfly diagram [27]. 
The hierarchy within the R-frameworks refers to the waste hierarchy/value-hill. The waste hierarchy concept originates in the prioritization of reduction, recycling, and reuse of waste over treatment or disposal [28,29]. The five-level waste hierarchy includes: 1. prevention, 2. reuse, 3. recycling, 4. other recovery, and 5. disposal [30].

The waste hierarchy is defined by [31] as:

"The waste hierarchy generally lays down a priority order of what constitutes the best overall environmental option in waste legislation and policy, while departing from such hierarchy may be necessary for specific waste streams when justified for reasons of, inter alia, technical feasibility, economic viability, and environmental protection."

An illustration of the technical and biological cycles can be found in Figure 1.

Recycling, for example, is at the end of the R-framework, since most recycling actually reduces the quality of a material over time [5] and thus is less circular than reusing a product. The first $\mathrm{R}$ is viewed as a priority for the second, and so on. This strengthens the statement that the R-framework together with the waste hierarchy are key CE aspects. In every additional production step within the supply-chain, we lose information about a product, or as T. Rau says: "Waste is material without an identity" [32] (p. 1). Meaning, the more information about raw materials that is registered and catalogued, the more waste going to the landfill can potentially be reduced. Figure 2 visualizes the 9R-framework.

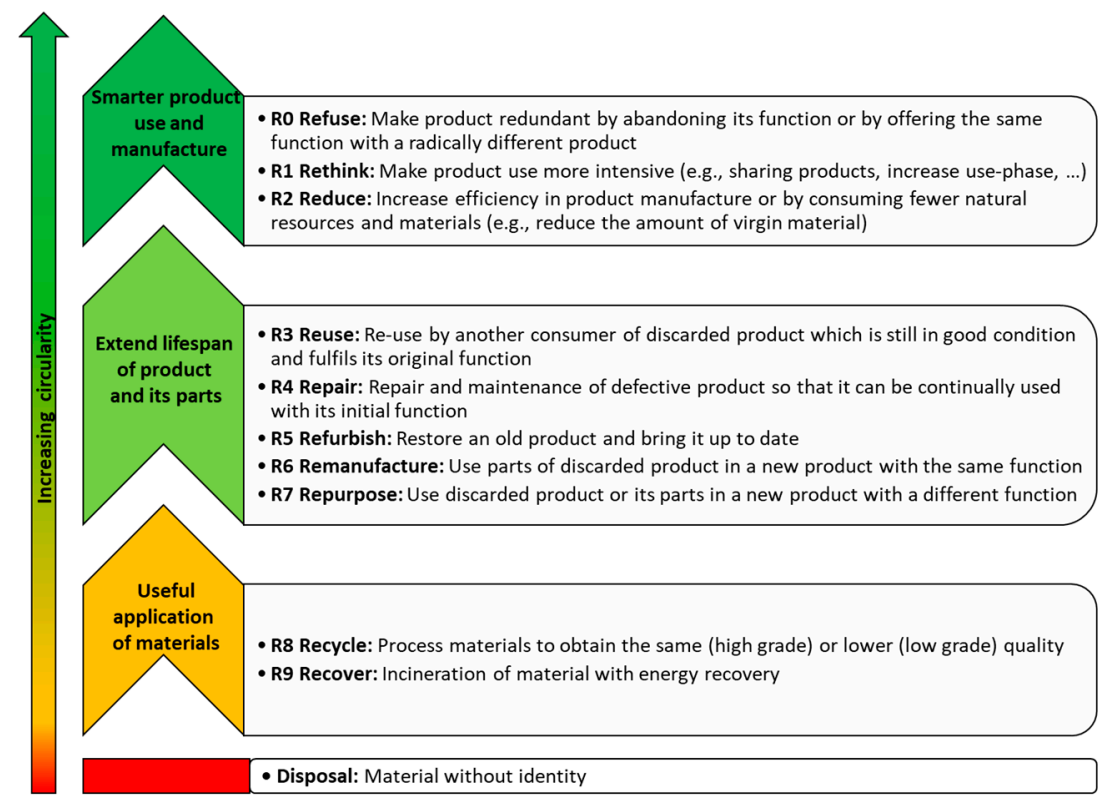

Figure 2. The 9R-framework, adapted from [5,33].

In the following section, the barriers and hurdles of the CE are reviewed, before the goals and targets of the CE are listed and summarized in a table.

\subsection{Barriers and Hurdles of the Circular Economy}

In most scholarly studies, various technological barriers (e.g., the tracking recycled material, maintaining product quality made from recovered material, design challenges, safe return challenges [6,34-36]) are blamed for limiting the progress of CE implementation. Contrary to these findings, Kirchherr et al. [13] proved through a large N-study that not only technical barriers hinder the successful application of CE. They divided the CE barriers accordingly to their relevance into:

1. cultural barriers (limited willingness to collaborate in the value chain [37], a lack of consumer awareness and interest [37], and operating in a linear system [38]); 
2. market barriers (low virgin material prices [15,37], a lack of standardization, high upfront investment costs [37,39,40], and limited funding for circular business models [38]);

3. regulatory barriers (limited circular procurement, the obstruction of laws and regulations [38]) and;

4. technological barriers (lack of data [38], non-circular product design [37], limited availability and quality of recycled material [41]).

The four above groups show the wide range of $C E$ barriers which exist throughout completely different domains. Other interesting approaches are to further divide the barriers into:

- hard (technical knowledge and gaps, technical solution availability, high initial costs, and market uncertainty) and soft (legal frameworks, taxes, educational set up, customer preferences) barriers [42];

- or external (capital support, policy support, and information support) and internal (tangible resources, intangible resources, capacity) barriers [43].

Further interesting barriers are the limited separation of waste, which stands in relation with the recovered quality [44] (cost versus quality [15]) and is due to a lacking waste management infrastructure [44]; perception of sustainability [45]; lacking IT systems for measuring and monitoring progress [44]; missing exchanges of information [45]; effective performance evaluation [43]; missing markets for product recovery [46]; high research and development costs [44]; decreased revenues at constant customer volumes [39]; weak cooperation throughout the supply-chain [44,45]; product design [45]; and hygiene issues [47]. For the plastics industry, additional barriers occur like unpredictable composition, content of impurities, quality issues, additives which are not altered during mechanical recycling, the influence of oil price on virgin material and consequently on recycled material, irregular and significant peaks of waste, a missing communication between plastics converters and plastics recyclers, and a misalignment between the collection and sorting infrastructure with the packaging design [48]. A final, more general hurdle is the need for technological improvements (e.g., Industry 4.0 (I4.0)) and innovation that enable leaner and cleaner manufacturing technologies as well as better recycling and reuse infrastructure $[49,50]$, so the synergy between CE and technology [51]. In this regard, Romero et al. [52] discuss the synergy between $\mathrm{CE}$ and I4.0, where digital technology transformation plays a crucial role towards CE. Kumar et al. [53] discuss the importance of I4.0, the subsequent digitalization of processes, and the holistic approach organizations need to adopt to remain competitive in supply-chains. Rajput and Singh [54] highlight the importance of information sharing and data-driven manufacturing systems with regard to CE.

As one can see, the list of barriers and hurdles within the CE is long and extensive. Since the aim of this paper is not to propose new hurdles, neither to propose a new subdivision, they are used as guidance and reference to consider the $C E$ in a holistic manner. The gained insight is used within the results and further discussed in the discussion section of the paper.

\subsection{Goals and Targets of the Circular Economy}

Morseletto [55] summarized the targets of the CE as: reduce waste, increase efficiency, close production loops, and maximize the retention of the economic value of materials and products. He considers three groups of targets, which encompass the $9 \mathrm{R}$-framework. The first group of targets relate to smarter product use and manufacture (R0-R2), the second group to extending the lifespan of a product and its parts (R3-R7), and the third group to the useful application of materials (R8-R9). Thus, the circularity of a product depends on the used technical cycle.

For Di Maio et al. [17], the key point of CE models is to maintain the added value in products for as long as possible and minimize waste. If products can no longer serve their functions, the aim of CE models is to keep the resources within the economy so that materials can be used again and therefore generate more value. This way, circular business 
models create more value from each unit of natural resource compared to traditional linear models.

Moraga et al. [16] divides CE into sensu stricto (slowing and closing resource loops) and sensu latu (sustainability). Slowing means extending and/or intensifying the utilization period of products, resulting in a slow-down of the flow of resources, whereas closing means to close the loop between post-use and production, resulting in a circular flow of resources. Thus, sensu stricto focuses on the technical cycle of resources. For sensu latu, CE is an economic model wherein planning, resourcing, procurement, production, and reprocessing are designed and managed, as both process and output, to maximize eco-system functioning and human wellbeing, thus pushing the focus on sustainability. This is similar to the three main approaches of Bocken et al. [56], which are slowing resource loops, closing resource loops, and reducing resource flows. The last approach focuses on resource efficiency and the narrowing of resource flows, aiming at using fewer resources per product.

For Elia et al. [57] the requirements to be measured are: the reduction of inputs and use of natural resources, emissions levels, valuable material losses, and the increase of sharing renewable and recyclable resources and the value durability of products. For Corona et al. [58], CE is perceived as a sustainable economic system where economic growth is decoupled from the resource use through the reduction and recirculation of natural resources. They provide eight $\mathrm{CE}$ validity requirements, listed in Table 1 . The EMF [59] bases CE on three principles: design out waste and pollution, keep products and materials in use, and regenerate natural systems.

For the sake of completeness, governmental aspects of the $\mathrm{CE}$ are included as well. The European Environmental Agency [60] identifies the following main policy questions concerning a life-cycle perspective: material input, eco-design, production, consumption, and waste recycling. Furthermore, two objectives are stated in their circularity gap report of 2021: minimize and regenerate production and extraction, as well as minimize the dispersion and loss of materials [61].

Parchomenko et al. [23] underline the importance of a globally accepted definition for the CE. They claim that the often-proclaimed goal of resource efficiency (often understood as producing more output from less input), misses the main goal of maintaining the value of products, parts, and materials over a maximum period. Linder et al. [62] claim that, whereas some definitions include the concepts of economic value and reduced energy consumption, the essence of the $\mathrm{CE}$ is related to the introduction of closed-loop product, resource, and material cycles to improve resource efficiency. Additionally, circularity metrics need to be robust against opportunistic behavior.

Usually, energy recovery is understood as the least preferred option [33,63]. However, the circular economy performance indicator (CPI) shows that for plastics the options should depend on the material quality. If the quality is low, recycling may result in higher environmental impacts than incineration $[16,64]$. Keeping resources in the loop at any price may be counterproductive. 
Table 1. Summary of CE goals.

Ref.

Reduce waste (2)

- $\quad$ Increase efficiency (3)

- $\quad$ Close production loops (1)

- Maximize retention of the economic value of materials and products (1)

- $\quad$ Maintain the added value in products for as long as possible (1)

- $\quad$ Minimize waste (2)

- If not possible, keep resources within the economy

- $\quad$ Sensu stricto: slowing and closing loops (1)

- $\quad$ Sensu latu: focus on sustainability (3)

- $\quad$ Slowing resource loops (1)

- $\quad$ Closing resource loops (1)

- $\quad$ Resource efficiency (3)

- $\quad$ Reducing input and use of natural resources (1)

- $\quad$ Reducing emissions levels (3)

- $\quad$ Reducing valuable material losses (2)

- $\quad$ Increasing shares of renewable and recyclable resources (1 and 3)

- Increasing value durability of products (1)

- $\quad$ Reducing: input of resources, especially scarce ones (1), emission levels (pollutants and GHG emissions) (3), material losses/waste (2)

- Increasing: input of renewable and recycled resources (1 and 3), utility and durability of products (1), local jobs at all skill levels (3), value-added creation and distribution (3), increase social wellbeing (3)

- $\quad$ Design out waste and pollution (2)

- $\quad$ Keep products and materials in use (1)

- $\quad$ Regenerate natural systems (3)

- $\quad$ Material input (1)

- $\quad$ Eco-design (1, 2, and 3)

- $\quad$ Production (2 and 3)

- $\quad$ Consumption (3)

- Waste recycling (2)

- $\quad$ Objectives: minimize resource extraction and regenerate biomass production and extraction (1); minimize dispersion and loss of materials (2)

- $\quad$ Strategies: narrow flows-use less (1); slow flows-use longer (1); regenerate flows-make clean (3); cycle flows-use again (1)

Table 1 summarizes the mentioned goals, including numbers to categorize similar goals.

As the included numbers show, all the goals can be linked towards three main goals.

1. Close and slow loops (Sensu stricto)

2. Minimize waste

3. Sustainability (Sensu latu) 
Based on the introduction and the three fields of the literature review, a misalignment between aiming to implement CE principles and applying them in a holistic manner has become apparent. This leads to an identified gap, which is a missing strategy to apply CE principles in a holistic manner, mainly due to incomplete communications.

The next chapter explains the used research methodology of this work in more detail before Section 4 proceeds with the obtained insights.

\section{Research Methodology}

To be more open-minded and flexible about potentially new ideas and findings, inductive research was chosen. Since the CE topic is a rather recent topic and trend which requires innovative perspectives, the advantages of open-mindedness and flexibility were chosen over the disadvantages of incompleteness and thus partially false conclusions, which can be listed as disadvantages of inductive compared to deductive research.

The research methodology is described in Figure 3, starting with an issue statement, followed by a descriptive literature review and a gap definition, which is covered by an analytical results section and an iterative feedback loop. A supply-chain (SC) consists of all parties involved in fulfilling a customer request [65], whereas the product-life-cycle (PLC) is the consecutive and interlinked stages of a product system, from raw material acquisition to final disposal [66]. Further information about how to build a circular supply-chain, can be found in [67].
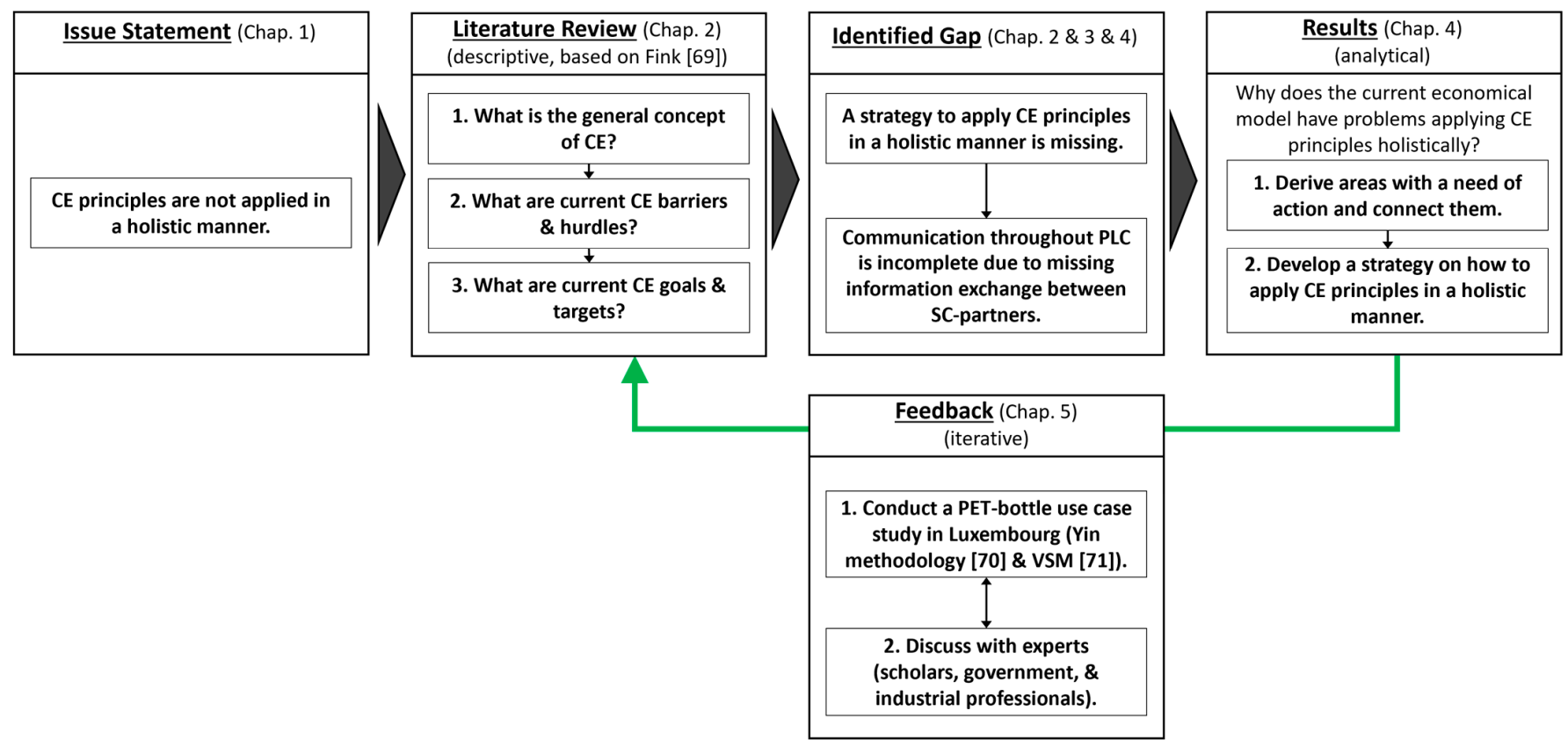

Figure 3. Research methodology.

Based on the identified gap, the aim of this work was to present a strategy to enable a system change towards the CE in SCs, or put differently, a strategy on how to apply CE principles in a holistic way. This strategy will be driven by EOL aspects, so mainly by the collection, sorting, and recovery capabilities of the respective organizations.

The literature review aims to create an overview of the scientific research on the CE concept in general and its barriers and hurdles, goals and targets, identifying themes and conceptual content in the literature [68]. To ensure a systematic review, the literature study was inspired by Fink [69]. This assures a systematic approach through the review and enables a replicability of the results and an actualization of the literature over time. First, the keywords in the three fields were defined (e.g., CE, barriers, goals, etc.), which were then used in several online bibliographies to focus on the newer, high-ranked publications. After reviewing these publications manually, the bibliographies of the respective 
publications were used to look for further, older publications, ensuring that only relevant literature was used (see Section 2). The next task was to examine the gained insights and incorporate them in an illustrative PLC. On this basis, two areas with a need for action were derived and a possibility on how to best connect both was elaborated. The solution is an information exchange between those responsible at the EOL (collection, sorting, and Rinfrastructure) and those responsible at the BOL (designers). This output was incorporated into a new strategy (see Section 4), which was tested against the elaborated CE barriers (see Section 5). To receive feedback about the strategy itself, a cross-company case study of a complete SC was performed using the example of a PET-bottle in Luxembourg. The Yin methodology [70] was used to structure the case study and the value stream mapping (VSM) [71] method was used to collect and visualize production-related information. The results of the case study will be presented in future publications. In addition to this, several discussions were held with $\mathrm{CE}$ and industrial experts. On the one hand, these discussions took place with scientific researchers and governments responsible during presentations of the project, and on the other hand with industry professionals during the VSM analysis. The discussions were held in an informal manner and the received feedback was used to re-adapt the strategy.

\section{Results}

The following chapter uses the previously gained insights to firstly outline two areas with a need for action to enable a successful CE implementation and secondly to develop a new strategy about how to apply CE principles in a holistic way.

\subsection{Areas with a Need for Action to Enable a CE}

To locate areas with a need for action, the butterfly diagram from EMF [26] is redrawn with the gathered information. First, the process steps (see Figure 2) are extended by two additional steps from the product life phases known from CAx [72], the product planning and product development. Within the biological cycle, a product gets consumed, whereas in the technical cycle a product gets used, which explains the distinction between consumer and user. Additionally, a material manufacturer is included, and the collection process is extended towards collection and sorting. Secondly, the different cascades are replaced by the 9R-framework [5], which is subdivided by colours into R2-R0: green; R7-R3: light green; R9-R8: orange; and linear economy: red. The result is an adapted butterfly diagram, focussing on the needs of a production supply-chain, respecting the principles of $\mathrm{CE}$ throughout the PLC.

Figure 4 shows the adapted butterfly diagram, which is explained hereinafter. 


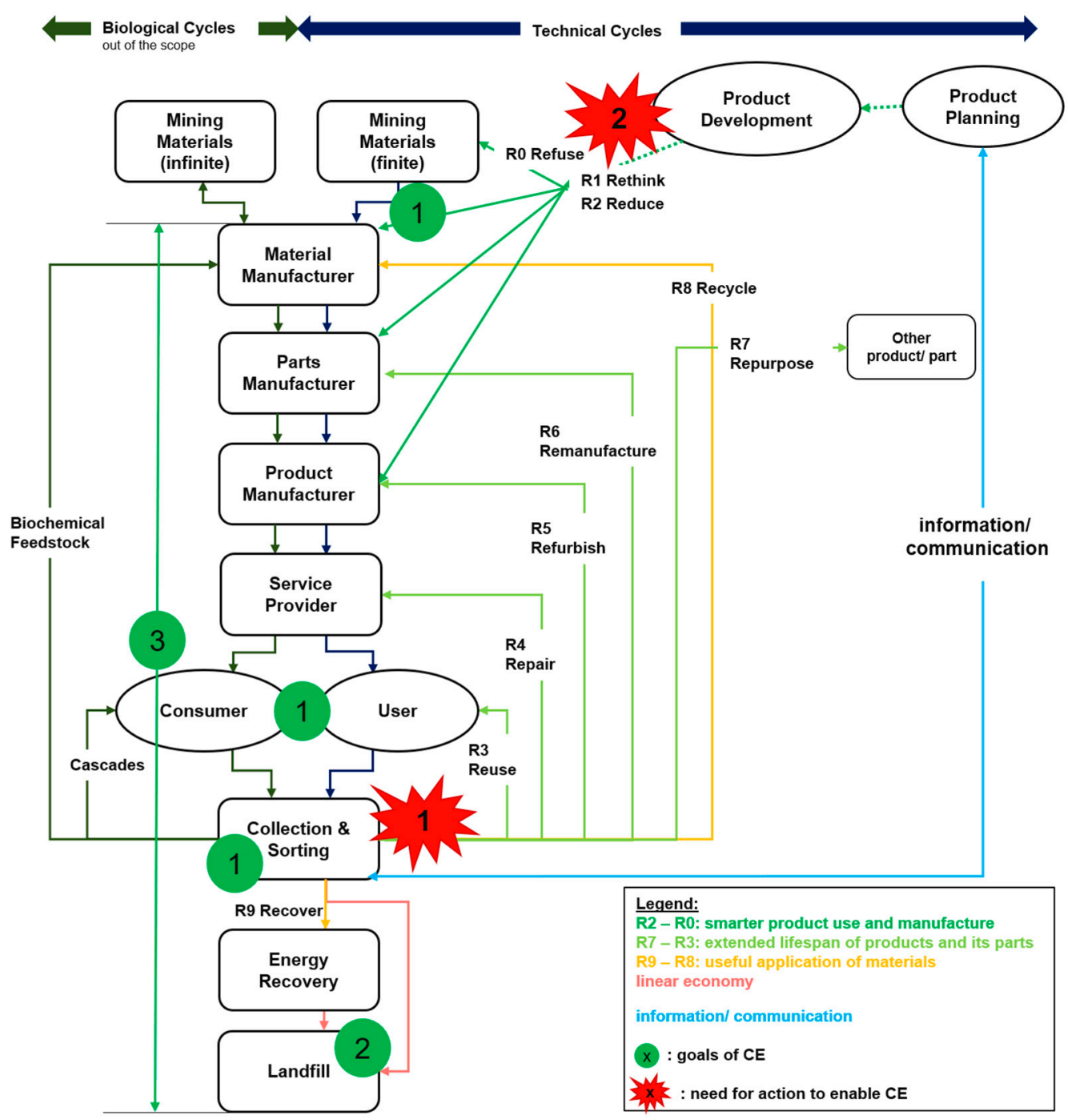

Figure 4. Adapted butterfly diagram, based on [26].

The next step is to introduce the previously mentioned goals into the diagram, aiming to highlight important areas. The first subgoal, "closing loops", applies at the beginning and end of (linear) products. This occurs at the end of the actual use phase of products and at the beginning of a product's life: the design phase. The first problem can be solved by setting up the needed infrastructure to catch products at the end of their use phase. The second problem can be addressed by reducing or refusing the use of virgin material, linked towards the design of products. For both cases, this is visualized by a 1 in a green circle at the collection and sorting process and between the mining of materials and the manufacturer. The second subgoal, "slowing loops" affects the use or consume phase. The slowing of the loops is achieved through longer usage, which is dependent on user or consumer behaviour as well as on the design of products. Since the closing of loops is already visualized by a 1 at the beginning of the product life-cycle, this subgoal is visualized by a 1 in a green circle at the user and consumer step. The second goal, "minimization of waste", applies at the landfill phase. To reduce or prevent waste, no more resources should follow the linear flow and end up at the landfill or as littering in nature. Therefore, the necessary infrastructure to intercept resources before they end up at landfill needs to be in place, as does reliable design to create circular and not linear products. The design sets the limits for the later uptake. This is visualized by a 2 in a green circle at the landfill process, aiming to reduce the landfill flow towards zero. The third goal, "sustainability", is valid 
during the complete PLC, and thus is visualized by a 3 in a green circle along the complete process chain.

This emphasizes two main perceptions. The first is the fact that all Rs, except R2-R0, start at the collection and sorting process. This shows that in order to enable R9 to R3, it is necessary that a specific infrastructure is in place. This is valid for the lower Rs, e.g., energy recovery or recycling, as it is for higher Rs like reuse or repair. For recycling, an infrastructure needs to be in place to recover materials (e.g., plastic), and for reuse, it needs to be assured that a certain infrastructure exists to supply reused products. Depending on the aim of resource retake (R9-R3) a respective infrastructure needs to be in place. Thus, identifying the necessary local or regional collection, sorting, and R-infrastructure is the first need for action. The second perception is that the higher category of Rs (R2-R0) is only achievable through an adapted product design. R1, rethink, for example, can only be achieved during the design phase of a product. The same is valid for R0, refuse. This could either be to refuse the usage of any virgin material or to leave a certain packaging of a product out completely. Therefore, developing certain circular product design guidelines is the second need for action.

The two needs for action are marked by a red star and are the following:

1. Identifying the needed collection, sorting, and R-infrastructure;

2. Developing circular product design guidelines.

The next question which arises is how both need for actions can be linked. Essentially, this is only possible through an improved exchange of information between the collection, sorting, and R-infrastructure and the product design or more precisely the product planning. It should also be mentioned that more than one $\mathrm{R}$ can be applied per product or resource. If R2 (reduce) is applied during the designing phase, it is still important that a certain infrastructure is in place to catch the product or material later during its life-cycle. Our proposition is thus to elaborate the $\mathrm{CE}$ design guidelines in accordance with the available and needed collection, sorting, and R-infrastructure, and thus connect the EOL with BOL, meaning that a design can only be as good as its respective infrastructure required to retake the resources. Therefore, an additional link which should visualize the need for information exchange and communication between the collection, sorting, and R-infrastructure and the design of products is included in the adopted butterfly diagram by a blue connection line. This could avoid the problem of only focussing on the design phase and thus creating new problems. If laws are to be set that every product needs to consist out of at least a certain percentage of recycled material, without considering the EOL of these products, it will become more and more difficult to find or raise material which can be recycled with adequate quality.

The following example illustrates the proposition. In Luxembourg, PET-bottles are automatically sorted via NIR-sensors according to their colour. Transparent and light blue bottles are forwarded to recycling facilities which produce PET-bottles, whereas green and darker bottles are forwarded to other industries. In this case, one condition based on the available infrastructure for a design aiming for direct PET-bottle recyclability is the colour. In the case that no sorting facility is available, the required infrastructure first needs to be put in place before CE principles can be applied. Thus, the CE design guidelines need to be in accordance with the available infrastructure.

The proposition to elaborate design guidelines on the respective R-infrastructure can be categorised in the Design for X (DfX), or more specifically within the design for circularity framework. An extensive review of a wide range of DfX approaches can be found in [73], defining DfX as "a combination of eco-design strategies" [62] (p. 3) and naming the following five design strategies: design for circular supplies, design for resource conservation, design for multiple cycles, design for the long-life use of product, and design for systems change. Further information can be found in [56,74-77] and information about a user-centred design can be found in [78]. However, none of these provide a method to directly connect the EOL and BOL, thus basing design guidelines on the available collection and sorting and R-infrastructure. 


\subsection{Strategy on how to Apply CE Principles in a Holistic Way}

The overall framework of the new strategy is summarized in Figure 5. It is based on the fact that the gathering of information should start at the EOL, as well as at the collection and sorting phase, and flow from here on towards the BOL design phase. From the use/consume phase, the information flow should flow in both directions. The users consumers should be informed about the product characteristics, whereas at the same time the habits of said users/consumers should be considered as well. The resource flow itself should flow according to the three previously mentioned goals (closed and slowed loops, minimized waste, according to three pillars of sustainability), while preventing virgin resource inflow and resource outflow through a well-coordinated consultation between the EOL and BOL. In doing so, we ensure that the collection, sorting, and R-infrastructure is always up to date with the newest product design trends and that users/consumers know exactly how to treat a product after its actual use phase. This can be summarized as EOL-driven product design, based on the three identified goals of the CE.

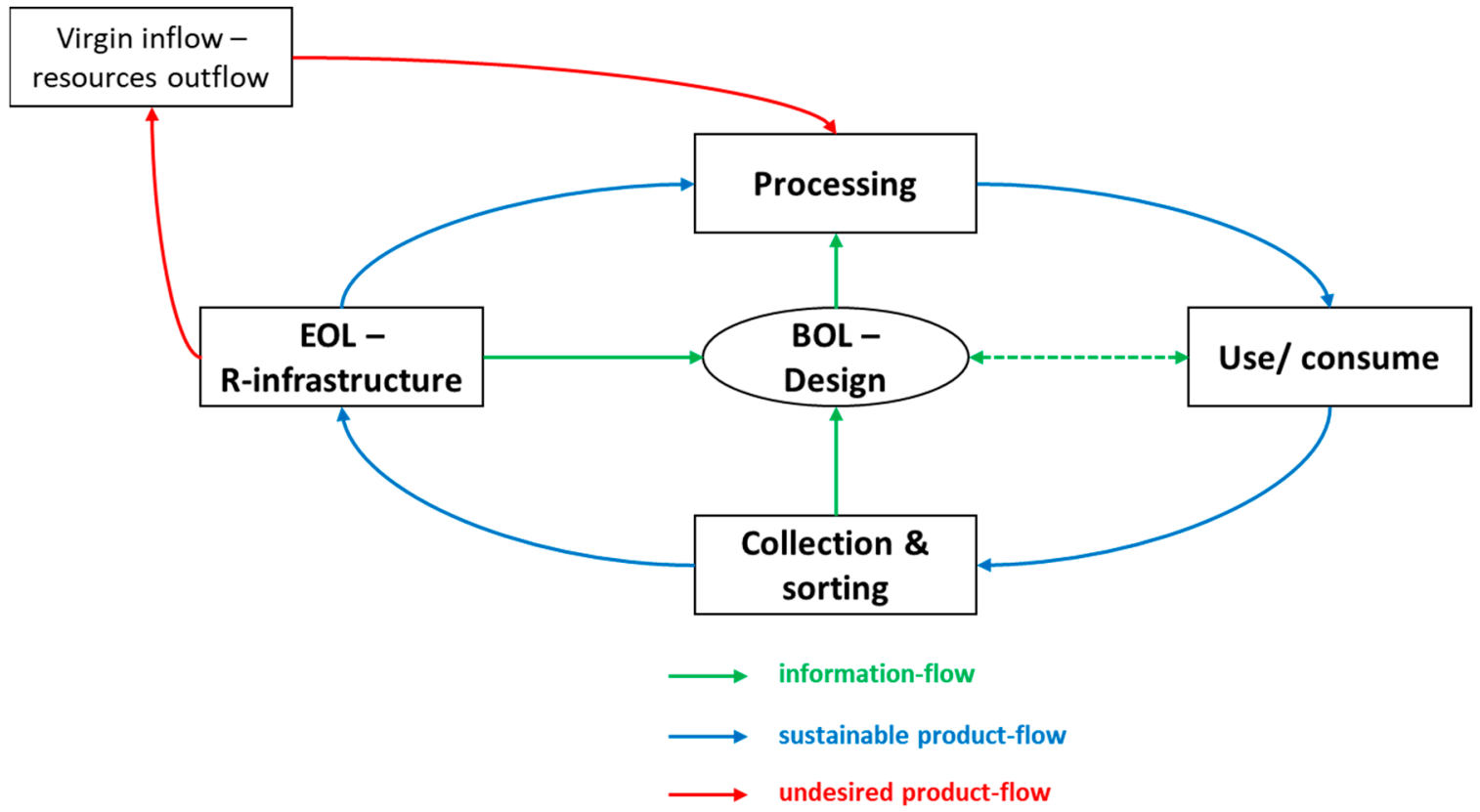

Figure 5. Strategy to enable a system change towards the CE.

Within Figure 5, the green arrows visualize the information flow, the blue arrows the sustainable product flow, and the red arrows the undesired, linear product flow. The direction of the arrow indicates the respective direction of the information or product flow. The different rectangles display the different product-life-cycle stages in a simplified manner, whereas the processing (or production) and use/consume phase can be seen as middle-of-life (MOL).

At this point, it should be made clear that this strategy is in no way intended to contradict technological improvements. On the contrary, as new product designs should always be created in consideration of the existing or required retake infrastructure. Thus, it only makes sense to bring new circular product designs on the market when the necessary infrastructure is in place. Thus, the necessary preparations need to be taken first. Most importantly, a separate development of product design and retake infrastructure should be avoided at all costs.

In addition, however, care should be taken to ensure that existing product designs can continue to be incorporated. The same applies to new business models (e.g., sharing economy), which should follow the same mindset. This is also an important aspect regarding regional differences. A product design which can be retaken in region A may not be retaken in region $\mathrm{B}$. 
The next two chapters discuss the results and conclude with further research directions.

\section{Discussion}

Even though not all the listed barriers (see Section 2.1) are covered by the proposed strategy, the following barriers perfectly match. The mentioned barriers of missing communication between plastic converters and plastic recyclers and a misalignment between the collection and sorting infrastructure with the packaging design are perfectly in accordance with the outcome of this work. Additionally, the lacking waste management infrastructure and technical solutions availability match with the R-infrastructure consideration at the EOL; the non-circular product designs match with CE design guidelines at the BOL; and the missing perception of sustainability correspond to the sustainable production and product flow. From a wider perspective, the following barriers can be included: limited willingness to collaborate in the value chain, lack of data, limited availability and quality of recycled material, and missing market for product recovery.

The presented results are in line with the currently discussed research directions of other authors and extends these by combining several ideas within one holistic approach Thus, the proposed strategy represents an important step to forward CE thinking towards more holistic considerations.

Another important aspect is the proposition to elaborate CE design guidelines in accordance with the available and needed collection, sorting, and R-infrastructure, and thus connect EOL with the BOL. This argument is not meant to contradict the need to improve the currently available recovery infrastructure, meaning the technological progress (see Section 2.2), but more a mutual support, so a hand-in-hand improvement. Meaning that, whenever the available infrastructure is improved, it is theoretically possible to recover more resources. However, if the product design changes again in the meantime, it may be the case that the R-infrastructure in place may be one step behind and thus is not able to recover more resources due to a misaligned dimensioning. In most cases, it is easier to adapt the product design instead of the infrastructure, which does not mean that the infrastructure should not be improved accordingly over time. The designers, manufacturers, and R-infrastructures responsible need to be encouraged to collaborate and create synergies and use technological enablers more specifically. The desired data sharing throughout complete SCs of the presented strategy (improved communication) is in line with the required digitalization technology and data-driven manufacturing systems, highlighted by other researchers $[50,52]$, necessary to enable a system change towards the CE.

An illustrating example from the packaging industry is the upcoming trend of biodegradable packaging. In this case, the design itself is well thought-out and an interesting idea to solve major pollution problems. However, without the needed infrastructure (e.g., sorting and industrial biodegradable facilities), these well-intentioned packaging will mostly end up within the technological cycles, potentially downgrading them. Thus, the locally available infrastructure always needs to be in compliance with the design of products, but often they ends up being one step behind. It would be easier for the BOL to adapt towards the needs and possibilities of the EOL instead of the other way around. Therefore, it would be easier to set up certain design guidelines (still allowing a certain scope for product development) which are in accordance with the available infrastructure. At exactly this shortcoming, the missing information and communication exchange between EOL and $\mathrm{BOL}$, the explained strategy intervenes. In doing so, the three previously mentioned goals (closing and slowing loops, minimizing waste, and all in accordance with sustainability) should be achieved. In this regard, the amount of energy consumption and its origins play a crucial role in achieving successful system change without neglecting sustainable aspects. The adapted butterfly diagram helps other researchers or practitioners to better understand the CE in a holistic way.

In addition, further insights from the industry were gathered during the VSM analysis of a PET-bottle case study in Luxembourg, which enabled the gathering of information 
about one product throughout its complete PLC. This specific example illustrated the importance of the awareness of EOL capabilities while designing a product. New technologies, such as chemical recycling, enable the possibility of regenerating materials with new qualities, but only through the use of high levels of resources and under the condition that the product itself ends up at the correct facility (e.g., collection and sorting needs to be done correctly). Thus, the product design influences the overall outcome. Currently, most often used technology of mechanical recycling is dependent on the product design, because the quality of the recycled material is directly influenced by this (e.g., color, added barriers, label, etc.). This example strengthens the importance of the proposed strategy, in line with technological progress.

\section{Conclusions}

$\mathrm{CE}$ is currently a well-discussed topic in literature as well as in politics. Hence, a lot of efforts have already been applied to move away from the linear economy to a more circular concept. Nevertheless, major issues still need to be overcome to successfully sustain a CE paradigm change. One of the major issues is that $C E$ is still not uniformly defined at an international level, resulting in an excessive, inconsistent number of different methods, hindering a uniform applicability. In addition, several barriers (e.g., missing holistic approaches, misalignment between the collection and sorting infrastructure and the design) are hindering the successful implementation of the CE concept.

This work helps to overcome some burdens by presenting a new strategy to enable a successful system change towards CE. This was done by first having a closer look at the main aspects of $\mathrm{CE}$ and visualizing the circular product-life-cycle, based on the butterfly diagram and the 9R-framework. After this initial step, the goals and targets of CE are highlighted and the burdens preventing a successful system change were located. This led to the appearance of two areas with a need for action. The first area is the identification of the necessary collection, sorting, and R-infrastructure (so-called EOL), which is the starting point for most Rs (R9-R3). This means that without the required catching and reprocessing infrastructure, it is impossible to enable a circular resource flow. The second area is the development of circular product design guidelines, which satisfies the higher Rs (R2-R0) regarding design, the so-called BOL. Thus, this new strategy aims at connecting and enabling an information exchange between those two areas. To successfully change towards a $\mathrm{CE}$, it is indispensable that the $\mathrm{EOL}$ and the $\mathrm{BOL}$ cooperate, as the prevention of this isolates both parties allowing them to only focus on their own issues. The product design can only be as promising as the infrastructure to support a specific design.

The results of this work are in line with those of J. Grafström and S. Aasma [21] (Figure 4, p.11) who identified the area of recycling, with its in- and outflow of material, as crucial and highlight the connection towards the collection (EOL) and design (BOL) phases. In addition to this, Paletta et al., [48] mention a misalignment between the collection and sorting infrastructure with packaging design as one of the barriers for plastics recycling. An initiative, which is approaching the same goal from the opposite direction, is the product circularity data sheet (PCDS), which is aiming to share important product information from the BOL to the EOL through the establishment of an official standard communicating data system on the CE properties of products [79]. This does not mean that both initiatives are in contradiction, but that they should be used collectively.

Future research should focus on implementing the herein described strategy within practical use-cases. This could be done by developing new methods which enable the sharing of information from the EOL with the BOL to apply CE principles in a holistic manner. The sharing of this information and hand-in-hand collaboration between EOL and BOL would be a major step towards a paradigm change towards a more circular supply-chain and resource flows in general.

Author Contributions: Conceptualization, J.M., M.M. and P.P.; methodology, J.M., M.M. and P.P.; resources, J.M., M.M. and P.P.; writing-original draft preparation, J.M.; writing-review and editing, J.M., S.K., M.M. and P.P.; visualization, J.M.; supervision, M.M. and P.P.; project administration, J.M., 
M.M. and P.P.; funding acquisition, M.M. and P.P. All authors have read and agreed to the published version of the manuscript.

Funding: This research was funded by the Di-Plast project, which is supported by Interreg NWE. The project aims to improve the uptake of recycled plastic material (rPM) within the packaging and building sector. Di-Plast aims to improve processes for a more stable rPM material supply and quality. Find more details about the project Di-Plast at https: / / www.nweurope.eu/projects / project-search/ di-plast-digital-circular-economy-for-the-plastics-industry/ (accessed on 15 July 2021).

Institutional Review Board Statement: Not applicable.

Informed Consent Statement: Not applicable.

Conflicts of Interest: The authors declare no conflict of interest. The funders had no role in the design of the study; in the collection, analyses, or interpretation of data; in the writing of the manuscript; or in the decision to publish the results.

\section{References}

1. Merli, R.; Preziosi, M.; Acampora, A. How do scholars approach the circular economy? A systematic literature review. J. Clean. Prod. 2018, 178, 703-722. [CrossRef]

2. Kalmykova, Y.; Sadagopan, M.; Rosado, L. Circular economy-From review of theories and practices to development of implementation tools. Resour. Conserv. Recycl. 2017, 135, 190-201. [CrossRef]

3. Azevedo, S.G.; Godina, R.; Matias, J.C.D. Proposal of a sustainable circular index for manufacturing companies. Resources 2017, 6, 63. [CrossRef]

4. Bocken, N.M.P.; Olivetti, E.A.; Cullen, J.M.; Potting, J.; Lifset, R. Taking the Circularity to the Next Level: A Special Issue on the Circular Economy. J. Ind. Ecol. 2017, 21, 476-482. [CrossRef]

5. Kirchherr, J.; Reike, D.; Hekkert, M. Conceptualizing the circular economy: An analysis of 114 definitions. Resour. Conserv. Recycl. 2017, 127, 221-232. [CrossRef]

6. Ghisellini, P.; Cialani, C.; Ulgiati, S. A review on circular economy: The expected transition to a balanced interplay of environmental and economic systems. J. Clean. Prod. 2016, 114, 11-32. [CrossRef]

7. Murray, A.; Skene, K.; Haynes, K. The Circular Economy: An Interdisciplinary Exploration of the Concept and Application in a Global Context. J. Bus. Ethics 2017, 140, 369-380. [CrossRef]

8. Lieder, M.; Rashid, A. Towards circular economy implementation: A comprehensive review in context of manufacturing industry. J. Clean. Prod. 2016, 115, 36-51. [CrossRef]

9. Yuan, Z.; Bi, J.; Moriguichi, Y. The circular economy-A New Development Strategy in China. J. Ind. Ecol. 2006, 10, 4-8. [CrossRef]

10. Blomsma, F.; Brennan, G. The Emergence of Circular Economy: A New Framing Around Prolonging Resource Productivity. J. Ind. Ecol. 2017, 21, 603-614. [CrossRef]

11. Tanzer, J.; Rechberger, H. Setting the common ground: A generic framework for material flow analysis of complex systems. Recycling 2019, 4, 23. [CrossRef]

12. Muradin, M.; Foltynowicz, Z. The circular economy in the standardized management system. Amfiteatru Econ. 2019, 21, 670. [CrossRef]

13. Kirchherr, J.; Piscicelli, L.; Bour, R.; Kostense-Smit, E.; Muller, J.; Huibrechtse-Truijens, A.; Hekkert, M. Barriers to the Circular Economy: Evidence From the European Union (EU). Ecol. Econ. 2018, 150, 264-272. [CrossRef]

14. Gusmerotti, N.M.; Testa, F.; Corsini, F.; Pretner, G.; Iraldo, F. Drivers and approaches to the circular economy in manufacturing firms. J. Clean. Prod. 2019, 230, 314-327. [CrossRef]

15. Kinnunen, P.H.M.; Kaksonen, A.H. Towards circular economy in mining: Opportunities and bottlenecks for tailings valorization. J. Clean. Prod. 2019, 228, 153-160. [CrossRef]

16. Moraga, G.; Huysveld, S.; Mathieux, F.; Blengini, G.A.; Alaerts, L.; Van Acker, K.; De Meester, S.; Dewulf, J. Circular economy indicators: What do they measure? Resour. Conserv. Recycl. 2019, 146, 452-461. [CrossRef]

17. Di Maio, F.; Rem, P.C.; Baldé, K.; Polder, M. Measuring resource efficiency and circular economy: A market value approach. Resour. Conserv. Recycl. 2017, 122, 163-171. [CrossRef]

18. Meadows, D.H.; Meadows, D.L.; Randers, J.; Behrens, W.W., III. The Limits to Growth; Universe Books: New York, NY, USA, 1972

19. Keeble, B.R. The Brundtland Report: 'Our Common Future'. Med. War 1987. [CrossRef]

20. Biermann, F.; Kanie, N.; Kim, R.E. Global governance by goal-setting: The novel approach of the UN Sustainable Development Goals. Curr. Opin. Environ. Sustain. 2017, 26-27, 26-31. [CrossRef]

21. ISO. ISO Guide 82:2019. Guidelines for Addressing Sustainability in Standards. Available online: https://www.iso.org/standard/ 76561.html (accessed on 15 July 2021).

22. Purvis, B.; Mao, Y.; Robinson, D. Three pillars of sustainability: In search of conceptual origins. Sustain. Sci. 2019, 14, 681-695. [CrossRef]

23. Parchomenko, A.; Nelen, D.; Gillabel, J.; Rechberger, H. Measuring the circular economy-A Multiple Correspondence Analysis of 63 metrics. J. Clean. Prod. 2019, 210, 200-216. [CrossRef] 
24. Braungart, M.; McDonough, W.; Bollinger, A. Cradle-to-cradle design: Creating healthy emissions-A strategy for eco-effective product and system design. J. Clean. Prod. 2007, 15, 1337-1348. [CrossRef]

25. Geissdoerfer, M.; Morioka, S.N.; de Carvalho, M.M.; Evans, S. Business models and supply chains for the circular economy. J. Clean. Prod. 2018, 190, 712-721. [CrossRef]

26. EMF. Towards a Circular Economy: Business Rationale for an Accelerated Transition; Ellen MacArthur Foundation: Cowes, UK, 2015; p. 20.

27. Saidani, M.; Yannou, B.; Leroy, Y.; Cluzel, F.; Kendall, A. A taxonomy of circular economy indicators. J. Clean. Prod. 2019, 207, 542-559. [CrossRef]

28. Pires, A.; Martinho, G. Waste hierarchy index for circular economy in waste management. Waste Manag. 2019, 95, 298-305. [CrossRef] [PubMed]

29. Van Ewijk, S.; Stegemann, J.A. Limitations of the waste hierarchy for achieving absolute reductions in material throughput. J. Clean. Prod. 2016, 132, 122-128. [CrossRef]

30. Rossi, V.; Cleeve-Edwards, N.; Lundquist, L.; Schenker, U.; Dubois, C.; Humbert, S.; Jolliet, O. Life cycle assessment of end-of-life options for two biodegradable packaging materials: Sound application of the European waste hierarchy. J. Clean. Prod. 2015, 86, 132-145. [CrossRef]

31. European Parliamanet and Council of the European Union. Directive 2008/98/EC of the European Parliament and of the Council of 19 November 2008 on Waste and Repealing Certain Directives (Text with EEA relevance). 2008. Available online: https: / / eur-lex.europa.eu/legal-content/EN/TXT/?uri=CELEX:32008L0098 (accessed on 15 July 2021).

32. Rau, T.M. Waste Is Material without an Identity. vol. 31, no. 0, pp. 1-15. 2017. Available online: http://houseful.eu/de/news/ passports-to-defend-the-rights-of-the-building-materials / (accessed on 15 July 2021).

33. Potting, J.; Hekkert, M.; Worrell, E.; Hanemaaijer, A. Circular Economy: Measuring Innovation in the Product Chain—Policy Report; PBL Netherlands Environment Assessment Agency: The Hague, The Netherlands, 2017; Volume 2544, p. 42.

34. Govindan, K.; Hasanagic, M. A systematic review on drivers, barriers, and practices towards circular economy: A supply chain perspective. Int. J. Prod. Res. 2018, 56, 278-311. [CrossRef]

35. Shahbazi, S.; Wiktorsson, M.; Kurdve, M.; Jönsson, C.; Bjelkemyr, M. Material efficiency in manufacturing: Swedish evidence on potential, barriers and strategies. J. Clean. Prod. 2016, 127, 438-450. [CrossRef]

36. Singh, J.; Ordoñez, I. Resource recovery from post-consumer waste: Important lessons for the upcoming circular economy. J. Clean. Prod. 2016, 134, 342-353. [CrossRef]

37. Mont, O.; Plepys, A.; Whalen, K.; Nußholz, J. Business Model Innovation for a Circular Economy Drivers and Barriers for the Swedish Industry-The Voice of REES Companies. 2017. Available online: http://lup.lub.lu.se/search/ws/files/33914256 /MISTRA_REES_Drivers_and_Barriers_Lund.pdf (accessed on 15 July 2021).

38. Pheifer, A.G. Barriers \& Enablers to Circular Business Models. 2017. Available online: https://www.circulairondernemen.nl/ uploads/4f4995c266e00bee8fdb8fb34fbc5c15.pdf (accessed on 15 July 2021).

39. Mangla, S.K.; Luthra, S.; Mishra, N.; Singh, A.; Rana, N.P.; Dora, M.; Dwivedi, Y. Barriers to effective circular supply chain management in a developing country context. Prod. Plan. Control. 2018, 29, 551-569. [CrossRef]

40. Rizos, V.; Behrens, A.; Kafyeke, T.; Hirschnitz-Garbera, M.; Ioannou, A. The Circular Economy: Barriers and Opportunities for SMEs; (CEPS Working Documents No. 412); CEPS: Brussels, Belgium, 2015.

41. Kok, L.; Wurpel, G.; Ten Wolde, A. Unleashing the Power of the Circular Economy; IMSA Amsterdam: Amsterdam, The Netherlands, 2013; pp. 1-48.

42. De Jesus, A.; Mendonça, S. Lost in Transition? Drivers and Barriers in the Eco-innovation Road to the Circular Economy. Ecol. Econ. 2018, 145, 75-89. [CrossRef]

43. Galvão, G.D.A.; de Nadae, J.; Clemente, D.H.; Chinen, G.; de Carvalho, M.M. Circular Economy: Overview of Barriers. Proc. CIRP 2018, 73, 79-85. [CrossRef]

44. Grafström, J.; Aasma, S. Breaking circular economy barriers. J. Clean. Prod. 2021, 292. [CrossRef]

45. Ritzén, S.; Sandström, G.Ö. Barriers to the Circular Economy-Integration of Perspectives and Domains. Procedia CIRP 2017, 64, 7-12. [CrossRef]

46. Tura, N.; Hanski, J.; Ahola, T.; Ståhle, M.; Piiparinen, S.; Valkokari, P. Unlocking circular business: A framework of barriers and drivers. J. Clean. Prod. 2019, 212, 90-98. [CrossRef]

47. Singh, P.; Giacosa, E. Cognitive biases of consumers as barriers in transition towards circular economy. Manag. Decis. 2019, 57, 921-936. [CrossRef]

48. Paletta, A.; Filho, W.L.; Balogun, A.L.; Foschi, E.; Bonoli, A. Barriers and challenges to plastics valorisation in the context of a circular economy: Case studies from Italy. J. Clean. Prod. 2019, 241, 118149. [CrossRef]

49. Mulvaney, D.; Richards, R.M.; Bazilian, M.D.; Hensley, E.; Clough, G.; Sridhar, S. Progress towards a circular economy in materials to decarbonize electricity and mobility. Renew. Sustain. Energy Rev. 2021, 137, 110604. [CrossRef]

50. Shayganmehr, M.; Kumar, A.; Garza-Reyes, J.A.; Moktadir, M.A. Industry 4.0 enablers for a cleaner production and circular economy within the context of business ethics: A study in a developing country. J. Clean. Prod. 2021, 281, 125280. [CrossRef]

51. D'Adamo, I.; Gastaldi, M.; Rosa, P. Recycling of end-of-life vehicles: Assessing trends and performances in Europe. Technol. Forecast. Soc. Chang. 2020, 152, 119887. [CrossRef] 
52. Romero, C.A.T.; Castro, D.F.; Ortiz, J.H.; Khalaf, O.I.; Vargas, M.A. Synergy between circular economy and industry 4.0: A literature review. Sustainability 2021, 13, 4331. [CrossRef]

53. Kumar, P.; Singh, R.K.; Kumar, V. Managing supply chains for sustainable operations in the era of industry 4.0 and circular economy: Analysis of barriers. Resour. Conserv. Recycl. 2021, 164, 105215. [CrossRef]

54. Rajput, S.; Singh, S.P. Industry 4.0 Model for circular economy and cleaner production. J. Clean. Prod. 2020, 277, 123853. [CrossRef]

55. Morseletto, P. Targets for a circular economy. Resour. Conserv. Recycl. 2020, 153, 104553. [CrossRef]

56. Bocken, N.M.P.; de Pauw, I.; Bakker, C.; van der Grinten, B. Product design and business model strategies for a circular economy. J. Ind. Prod. Eng. 2016, 33, 308-320. [CrossRef]

57. Elia, V.; Gnoni, M.G.; Tornese, F. Measuring circular economy strategies through index methods: A critical analysis. J. Clean. Prod. 2017, 142, 2741-2751. [CrossRef]

58. Corona, B.; Shen, L.; Reike, D.; Carreón, J.R.; Worrell, E. Towards sustainable development through the circular economy-A review and critical assessment on current circularity metrics. Resour. Conserv. Recycl. 2019, 151, 104498. [CrossRef]

59. Ellen Macarthur Foundation. What is a Circular Economy? A Framework for an Economy that is Restorative and Regenerative by Design. 2020. Available online: https://www.ellenmacarthurfoundation.org/circular-economy/concept (accessed on 10 December 2020).

60. EEA-European Environment Agency. Circular Economy in Europe-Developing the Knowledge Base; EEA Rep. No 2/2016; European Environment Agency: Copenhagen, Denmark, 2016; p. 37.

61. Circle Economy. The Circularity Gap Report 2021; Circle Economy: Amsterdam, The Netherlands, 2021.

62. Linder, M.; Sarasini, S.; van Loon, P. A Metric for Quantifying Product-Level Circularity. J. Ind. Ecol. 2017, 21, 545-558. [CrossRef]

63. Ellen Macarthur Foundation. Towards the Circular Economy-Economic and Business Rationale for an Accelerated Transition; Ellen Macarthur Foundation: Cowes, UK, 2013; p. 100.

64. Huysman, S.; de Schaepmeester, J.; Ragaert, K.; Dewulf, J.; de Meester, S. Performance indicators for a circular economy: A case study on post-industrial plastic waste. Resour. Conserv. Recycl. 2017, 120, 46-54. [CrossRef]

65. Chopra, S.; Meindl, P. Supply Chain Management_Strategy, Planning, and Operation, 5th ed.; Pearson Education: London, UK, 2013; Volume 53.

66. ISO. ISO 14040:2006. Environmental Management-Life Cycle Assessment-Principles and Framework. Available online: https: / / www.iso.org/standard/37456.html (accessed on 15 July 2021).

67. González-Sánchez, R.; Settembre-Blundo, D.; Ferrari, A.M.; García-Muiña, F.E. Main dimensions in the building of the circular supply chain: A literature review. Sustainability 2020, 12, 2459. [CrossRef]

68. Meredith, J. Theory Building through Conceptual Methods. Int. J. Oper. Prod. Manag. 1993, 13, 3-11. [CrossRef]

69. Fink, A. Conducting Research Literature Reviews-From the Internet to Paper, 5th ed.; SAGE Publications, Inc.: Los Angeles, CA, USA, 2019.

70. Yin, R.K. Case Study Research and Applications: Design and Methods, 6th ed.; SAGE Publications, Inc.: Los Angeles, CA, USA, 2018.

71. Mangers, J.; Oberhausen, C.; Minoufekr, M.; Plapper, P. Creation of an ISO Standard at the Example of Value Stream Management Method. In Shaping the Future Through Standardization; IGI Global: Hershey, PA, USA, 2020; pp. 1-26.

72. Vajna, S.; Weber, C.; Zeman, K.; Hehenberger, P.; Gerhard, D.; Wartzack, S. CAx für Ingenieure-Eine Praxisbezogene Einführung; Springer: Berlin, Germany, 2018.

73. Moreno, M.; de los Rios, C.; Rowe, Z.; Charnley, F. A conceptual framework for circular design. Sustainability 2016, 8, 937. [CrossRef]

74. Bovea, M.D.; Pérez-Belis, V. Identifying design guidelines to meet the circular economy principles: A case study on electric and electronic equipment. J. Environ. Manag. 2018, 228, 483-494. [CrossRef]

75. Shahbazi, S.; Jönbrink, A.K. Design Guidelines to Develop Circular Products: Action Research on Nordic Industry. Sustainability 2020, 12, 3679. [CrossRef]

76. Sihvonen, S.; Ritola, T. Conceptualizing ReX for aggregating end-of-life strategies in product development. Proc. CIRP 2015, 29, 639-644. [CrossRef]

77. Van den Berg, M.R.; Bakker, C.A. A product design framework for a circular economy. In Proceedings of the PLATE-Product Lifetimes Environment Conference, Nottingham Trent University, Nottingham, UK, 17-19 June 2015; pp. 365-379. Available online: https://www.researchgate.net/profile/Giuseppe_Salvia/publication/303476076_Product_Lifetimes_And_The_ Environment_Conference_Proceedings/links/57447ba808aea45ee85306ca.pdf\#page=373 (accessed on 15 July 2021).

78. Selvefors, A.; Rexfelt, O.; Renström, S.; Strömberg, H. Use to use-A user perspective on product circularity. J. Clean. Prod. 2019, 223, 1014-1028. [CrossRef]

79. Ministry of the Economy of Luxembourg. Luxembourg Circularity Dataset Standardization Initiative. 2019. Available online: https:/ / gouvernement.lu/dam-assets / documents/actualites/2019/12-décembre/CircularDatasetInitiativePresentation.pdf (accessed on 15 July 2021). 